\title{
Modeling of high frequency high voltage of waveforms on life of enamel insulation
}

\author{
S. Narasimha Rao, Elanseralathan Kasinathan \\ Department of Electrical and Electronics Engineering, Puducherry Technological University, Puducherry, India
}

\begin{tabular}{l}
\hline \hline Article Info \\
\hline Article history: \\
Received May 21, 2021 \\
Revised Jul 30, 2021 \\
Accepted Aug 4, 2021 \\
\hline
\end{tabular}

\section{Keywords:}

Electric field distribution High switching frequency Modeling

Square-rising waveform Twisted-pair

\begin{abstract}
In recent years it has been observed that insulation failure in electrical motors is caused by adjustable speed drives fed by power electronic converters. These converters produce impulse waveforms having a high slew rate generated by the high switching frequency of IGBTs. This paper focuses on high switching frequency stress in low voltage electrical motors for adjustable speeds. To examine the motor winding insulation under such stress twisted-pair samples were developed from enameled wires. A singlecoated polyester of enamel with a thickness of 40 microns is used for this work. High-frequencies, high voltages of Square, and Square-rising, Squarespike waveforms of $10-30 \mathrm{kHz}$ are used here. The test results show that the insulation fails earlier for the Square waveform compared to the Squarespike and Square-rising waveforms. In a nutshell, there is an analysis of PD formation in the insulation system at a higher switching frequency is analyzed. Electric field distributions between twisted pairs with various air gaps of the insulation system stressed by the Square and Square-rising waveforms up to $30 \mathrm{kHz}$ are modeled using COMSOL software.
\end{abstract}

This is an open access article under the CC BY-SA license.

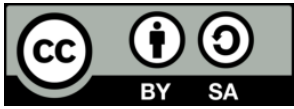

Corresponding Author:

S. Narasimha Rao

Department of Electrical and Electronics Engineering

Puducherry Technological University, Puducherry

Pillaichavadi, Puducherry, India 605014

Email: snrinskit@pec.edu

\section{INTRODUCTION}

In industrial drives, the control of speed is accomplished by using power electronic converters, using the PWM technique. This technology brought new developments in the speed control of industrial motors [1]. However, these converters generate high switching impulses at every instant of switching, which is of very high slew rate and high repetitive frequency produced by IGBT's. Due to this, the enamel insulation of the coil is subjected to repeated surge voltages with short rise times in the order of nanoseconds. These surges induce reliability problems in low and medium ratings of the motor insulation system [2]. As this waveform travels from the inverter to the motor end, the spike gets enhanced in magnitude due to the mismatch of impedance between the inverter, motor, and cable. The phenomenon of resonance and reflection can induce twice the supply voltage at the turn-to-turn insulation of stator winding [3], [4], which is the major reason for the unexpected failure of winding of insulation. Furthermore, the distribution of electrical potential is non-uniform across the windings [5], [6]. Hence, abnormal electrical stress is experienced by phase to phase winding of motor insulation, more stress than sine waveform [7], at the first turns of the insulation system [8], in particular. Owing to an overshoot in voltage peaks, the partial discharge takes place in winding because of which the lifetime of organic enameled insulation is remarkably short [9], [10]. 
Investigation of low-frequency stress is reported in the literature. However, as the enamel insulation may experience higher frequency, this work presents higher frequency stress of $10-30 \mathrm{kHz}$ of Square, Square-rising, and Square-spike waveforms. Testing with Square waveforms produces highest dv/dt that can cause high stress on the insulation when compared with other waveforms. The reason for choosing high frequency for the test is because of the growing demand for variable speed applications and the increasing number of low voltage motors [11]. The purpose of employing the high frequency switching in the present work is to examine the electric stress produced by the high-frequency pulses with the sharp rate of rise of voltage surge on the motor winding insulation.

The aging of enamel insulated wires was investigated using five different waveforms of a fundamental frequency of $300 \mathrm{~Hz}$ in the presence of PDs and reported that the life of enamel insulation is affected by the shape of the waveform [12]. The effect of short unipolar repetitive impulsive voltages with $200 \mathrm{~ns}$ voltage duration on PD statistics and insulation lifetime of enameled wires was studied [13]. It is reported that PD magnitude under unipolar short impulsive voltages with different rise times increase significantly with decreasing rise times. The life of two kinds of enamel wires of organic resin and nanofilled resin were studied and modeling of a lifetime was predicted [14]. I F Radzi et al. [15] argued that there is an improvement of degradation at long term by PD in a drastic way when the applied voltage is $6.5 \mathrm{kV}$ to $8.5 \mathrm{kV}$. Breakdown studies with a step of $50 \mathrm{~V} / \mathrm{s}$ for AC and a step of $100 \mathrm{~V} / \mathrm{s}$ for DC on thin-film insulation with a thickness of $100 \mu \mathrm{m}$ were done [16]. It is also reported that the breakdown strength of composites is lower compared to unfilled polypropylene. Researchers reported that the failure of twisted pair insulation is due to high repetition frequency initiating the partial discharge [17]. It is also reported that through the simulations the PD arises in the micro gap between the twists using the COMSOL software.

Though there are works done at a lower frequency up to $600 \mathrm{~Hz}$ and at $3 \mathrm{kHz}$, the life of insulation subjected to higher frequency pulses due to MOSFET or IGBT switching of up to $20-40 \mathrm{kHz}$ are needed to be known. The stator winding insulation is subjected to such high frequency stress which is a more realistic one. As observed by researchers that one cannot assume a theoretical deduction that low-frequency test data can be used to predict life with increasing frequency for all insulation systems, the test was done at $10 \mathrm{kHz}$ [18] but the objective was to save the power loss rather than to know the life of the insulation. Hence an attempt is made in this work to test the twisted pair insulation with the higher frequency of $10-30 \mathrm{kHz}$ to investigate the life of twisted pair enamel insulation. In the present study, the twisted-pair sample of polyester enamel is stressed by Square, Square-rising, and Square-spike waveforms over the range of frequencies from 10-30 kHz. The tests are performed to show that early failure of twisted pair insulation could be associated with PD phenomena attributed to higher switching frequencies. Field distribution at different air-gap lengths between twists with enamel thickness of $40 \mu \mathrm{m}$ at different switching frequencies in the range of $10-30 \mathrm{kHz}$ is numerically modeled using COMSOL. The simulations carried out showed that the electric field distribution depends on the air-gap length between the wires and insulation thickness.

The rest of the paper is organized as follows: Section 2 describes the experimental setup for breakdown tests, sample preparation, and test procedure. Section 3 discusses the experimental results and analyzed the influence of high switching frequency on twisted pair samples by modeling the electric field distribution with applied voltage and reduced breakdown voltage. Finally, section 4 concludes with the findings on breakdown voltage and rate of deterioration of the insulation system for Square waveform, Square-rising waveform, and Square-spike waveforms.

\section{EXPERIMENTAL PROCEDURE}

\subsection{Sample preparation}

The twisted-pair specimens are made of two enameled magnet wires twisted like a plait as per the ASTM D 1676-03 standards. A singly coated polyester enamel insulation with $40 \mu \mathrm{m}$ thickness is employed for testing. The twisted-pair length is maintained $(12 \pm 6) \mathrm{cm}$ as per standards. The number of twists is 6 , depending on the diameter of the wire.

\subsection{Test setup}

Figure 1 shows the experimental setup for Square, Square-rising, and Square-spike waveforms with high-frequency, the high voltage used for testing the twisted pair samples. All the waveforms used here are bipolar in nature. The $230 \mathrm{~V}, 50 \mathrm{~Hz}$ source is fed to the EMI line filter and the output is connected to the frequency and duty cycle controller. The output of the inverter is stepped up by employing a nanocrystalline core transformer for high frequency operation where the twisted pair sample is stressed. A digital oscilloscope measures the peak voltage through a 1000:1 capacitance voltage divider. The laboratory setup used for conducting the breakdown and withstand tests is shown in Figure 2. 


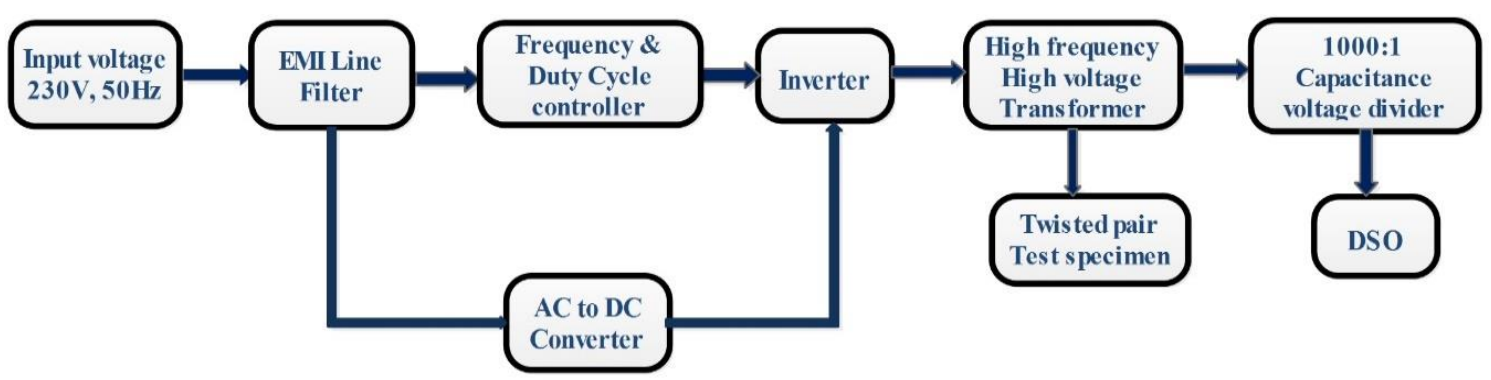

Figure 1. Experimental setup

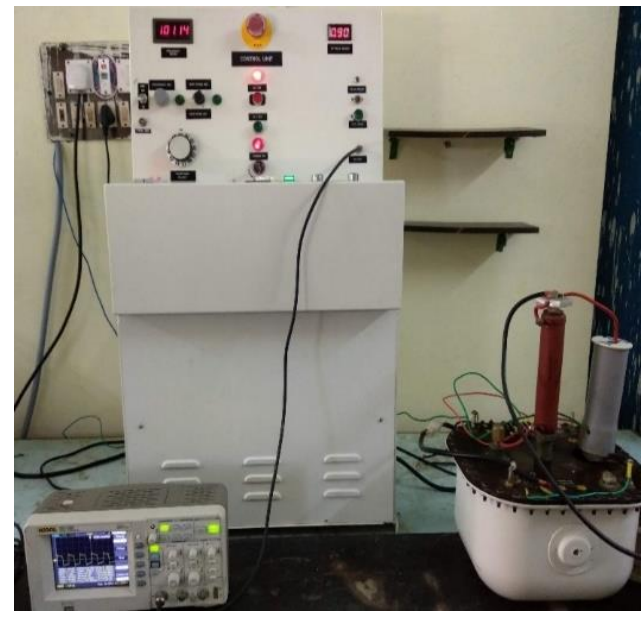

Figure 2. Laboratory setup used for breakdown tests

\subsection{Test procedure}

Breakdown tests were carried out on the twisted-pair specimens with the edge of one wire is fed with test voltage and edge another wire is grounded thus the layers of the enamel of both wires comes under high voltage stress. The breakdown test is performed by the application of a high voltage at the twisted-pair specimen until the sample insulation breakdowns. The withstand test was conducted to estimate the time up to which the insulation withstands without breakdown even under the application of various voltage levels. In this study, the breakdown voltage of the twisted-pair specimen is observed by enhancing the voltage at a rate of $500 \mathrm{Volt} / \mathrm{sec}$ up to breakdown. The breakdown experiments were done on insulation with enamel at room temperature under the application of a high-frequency high voltage of Square, Square-rising, and Squarespike waveforms and a frequency in the range of 10-30 kHz. Breakdown voltage is taken as the average of five breakdown values. It is noticed that, while performing the experiments at high-frequency, the ionization impact between the twisted-pair gaps is manifested in the form of a hazy violet glow. Reduced breakdown voltage is applied to the sample until the breakdown of the sample for the Withstand-test. For a certain frequency, the reduced voltage applied is $75 \%, 60 \%$, and $50 \%$ of the breakdown voltage of that particular frequency. Table 1 shows the parameters of the test setup used for breakdown tests.

Table 1. Test setup details

\begin{tabular}{cccc}
\hline Frequency & Duty cycle & Waveforms & Test operating voltage \\
\hline $10-30 \mathrm{kHz}$ & $0-50 \%$ & Sine, Square, Square-rising, and Square-spike & $0-15 \mathrm{kV}$ peak \\
\hline
\end{tabular}

\section{RESULTS AND DISCUSSION}

\subsection{Experimental results}

The variation in breakdown voltages over the frequency with waveforms is depicted in Figure 3. From the graph, it is evident that the Square, Square-rising and Square-spike waveforms exhibit two straight lines with varying slopes as in [19], with a rise in the frequency from 10-30 kHz. It is observed from the graphs the breakdown voltage of Square-rising waveform is more than that of Square-spike and Square 
waveforms. Therefore, it is described that the deterioration rate of the insulation system of twisted pair using Square waveform is quicker as compared to Square-spike and Square-rising waveforms, similar to the published results for PWM like and PWM peak waveforms reported in [20]. An attempt is made to compare the results obtained for Square spike with that of published results of PWM peak waveform. It could be that the Square wave has a steep rising and trailing edge that corresponds to high frequency components due to the shape of the waveform. There are quite different polarizing and relaxing effects on dipoles for a complete Square wave period [21]. It is because of this reason that there will be no possibility of more dipoles following the rapid reversal of the polarity. It is also observed that reduction in breakdown voltage is $27 \%$ in the Square waveform whereas 32\% in Square-spike waveform and 41\% in Square-rising waveform when the frequency is varied from 10-30 kHz. Figure 4 shows the aging test results stressed with a Square-rising waveform with various levels in frequency up to $30 \mathrm{kHz}$ at reduced voltages. It can be seen that the decrease in breakdown time follows a higher slope when the applied test voltage is changed from $75 \%$ to $60 \%$ and a lower slope when changed from $60 \%$ to $50 \%$ for all three frequencies though the change in slope is very less at $10 \mathrm{kHz}$. It is interesting to note that results in Figure 4(a) for Square-spike waveform point to a similar trend to that of published results for PWM-peak waveform reported in [12], for all three frequencies, though the results of Figure 4(b) is in contrast. This may be due to higher test voltages in Square-rising waveforms.

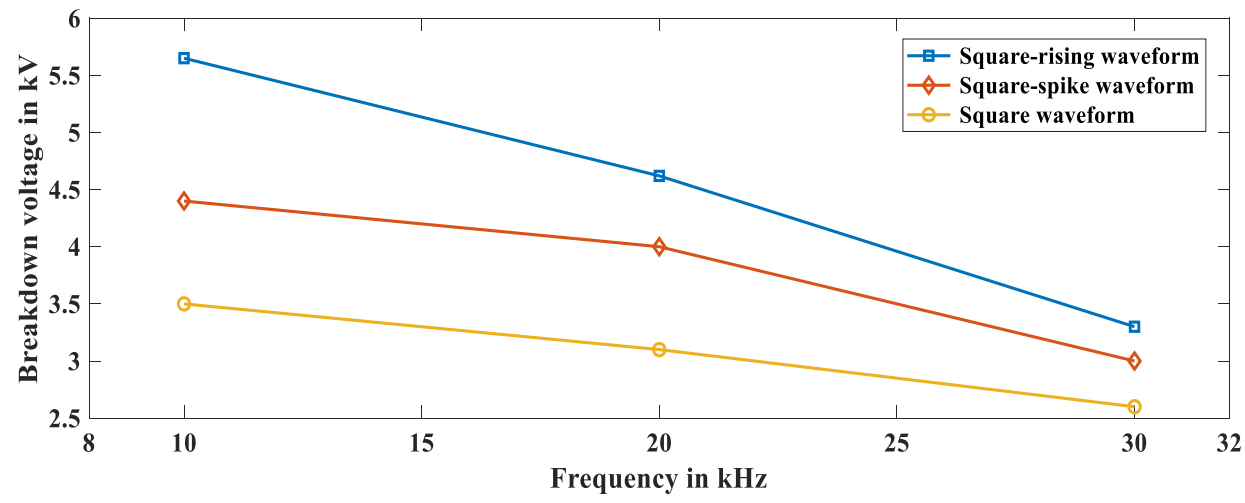

Figure 3. Variation in breakdown voltages of square, square-rising, and square-spike waveforms from 10-30 $\mathrm{kHz}$

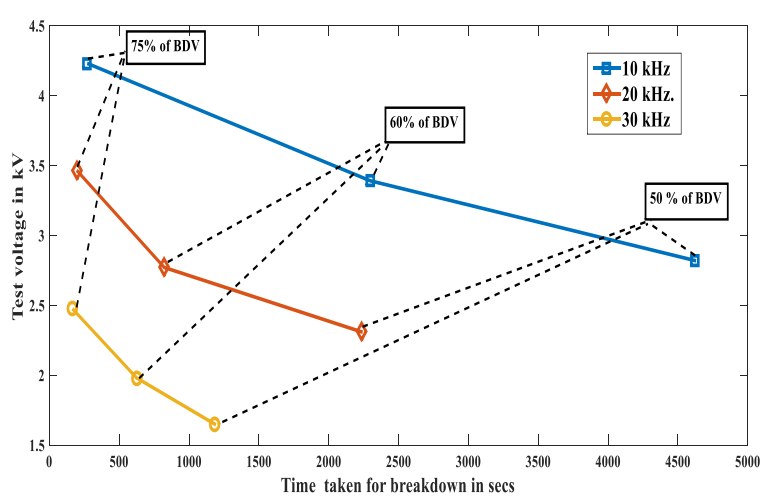

(a)

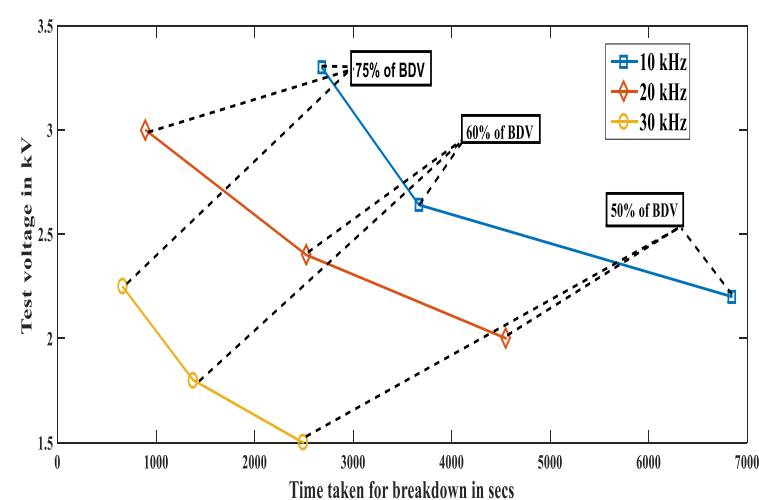

(b)

Figure 4. Aging test results at reduced voltage up to $30 \mathrm{kHz}$ stressed with (a) square-spike waveform (b) square-rising waveform

Figure 5(a)-(c) shows the aging test results when the twisted pair sample is stressed with Squarerising and Square-spike waveforms with frequency levels of $10 \mathrm{kHz}, 20 \mathrm{kHz}$, and $30 \mathrm{kHz}$ respectively with a reduced voltage of $75 \%, 60 \%$, and $50 \%$. When there is an enhancement in frequency from $10-30 \mathrm{kHz}$, Square-rising and Square-spike waveforms show the two straight-line slopes, whereas authors of [13], [22][24], reported uniform slopes of characteristics with various enamels for frequencies up to $8 \mathrm{kHz}$. The 
characteristics of the Square-spike waveform are observed to cross over the characteristics of the Squarerising waveform only for $10 \mathrm{kHz}$ in Figure 5(a). The breakdown occurs early for the Square-rising waveform than the Square-spike waveform due to the higher applied voltage in all the frequencies. The reason for lower breakdown voltage is that at higher switching frequency the ions getting trapped between the electrodes and rapid polarity changes, resulting in the distorted electrostatic field. Due to this space charge no longer follow the field due to the effect of polarization. PD may be influenced by surface charging caused pre-ionization of electric field strength.

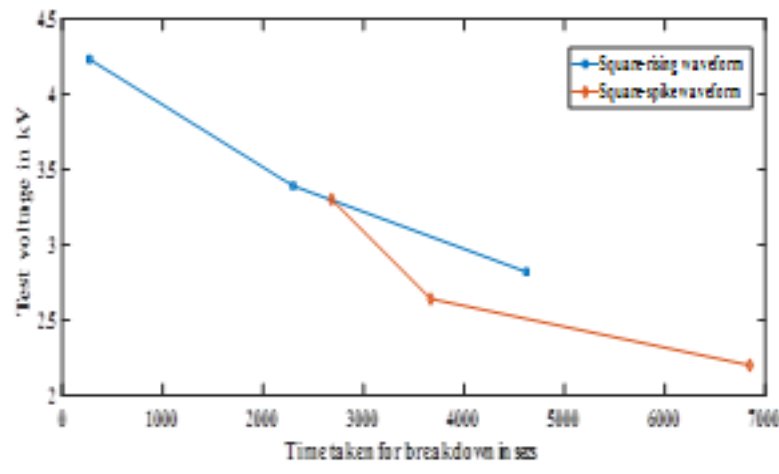

(a)

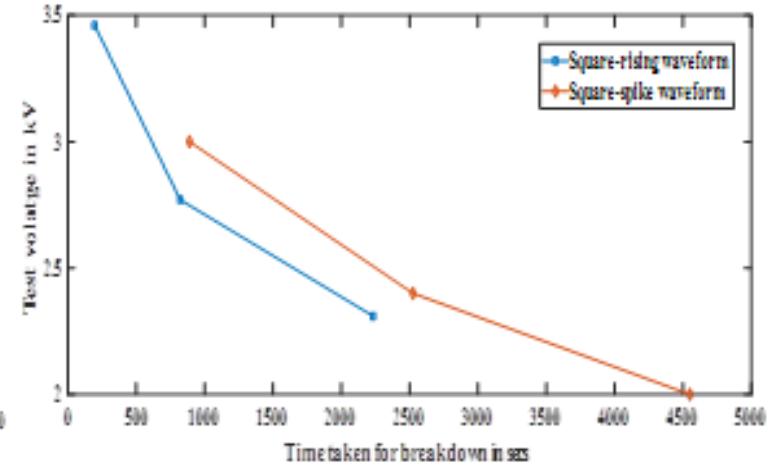

(b)

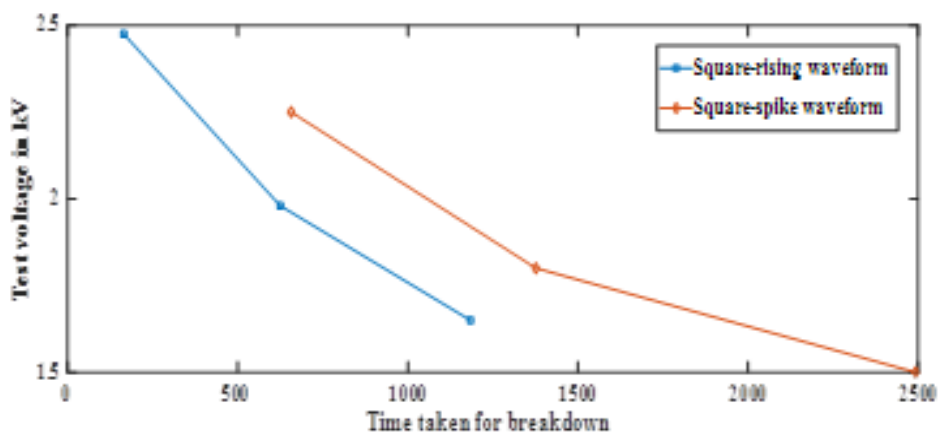

(c)

Figure 5. Aging test characteristics of square-rising and square-spike waveforms at frequencies of (a) $10 \mathrm{kHz}$, (b) $20 \mathrm{kHz}$, and (c) $30 \mathrm{kHz}$

Figure 6 shows the breakdown time when stressed with a reduced voltage of Square-rising and Square-spike waveforms up to $30 \mathrm{kHz}$. From Figure 6 (a) it is seen that breakdown time doesn't show any change when the frequency is enhanced from $10-30 \mathrm{kHz}$ when stressed with Square-rising waveform at a reduced voltage of $75 \%(4.23 \mathrm{kV})$. However, under the reduced voltage stress of $60 \%(3.39 \mathrm{kV})$, the breakdown time is decreased by $64 \%$ when the frequency is enhanced from $10-20 \mathrm{kHz}$ and by $24 \%$ from 20 $30 \mathrm{kHz}$. Similarly, at $50 \%(2.82 \mathrm{kV})$ breakdown time is decreased by $52 \%$ when the frequency is enhanced from $10-20 \mathrm{kHz}$ and decreased by $47 \%$ when the frequency is enhanced from $20-30 \mathrm{kHz}$. This shows the effect of frequency at $10 \mathrm{kHz}$ and $20 \mathrm{kHz}$ compared to $30 \mathrm{kHz}$ at reduced voltages. It is seen from Figure 6 (b) that breakdown time decreased with a higher slope when the frequency is enhanced from $10-20 \mathrm{kHz}$ and a lower slope from $20-30 \mathrm{kHz}$ when the reduced voltage of $75 \%(3.3 \mathrm{kV})$ for Square-spike waveform. However, when the voltage of $60 \%(2.64 \mathrm{kV})$, the breakdown time is decreased by $31 \%$ when the frequency is enhanced from 10-30 kHz. Similarly, at 50\% $(2.2 \mathrm{kV})$ breakdown time is decreased by $30 \%$ when the frequency is enhanced from $10-30 \mathrm{kHz}$. The significance of the finding is that the twisted pair enamel insulation undergoes severe electrical stress at high frequencies. At $10 \mathrm{kHz}$, the breakdown strength is 1.15 to $4.4 \mathrm{kV}$ times higher, 1.12 to $3.4 \mathrm{kV}$ times higher at $20 \mathrm{kHz}$, and at $30 \mathrm{kHz} 1.25$ to $2.1 \mathrm{kV}$ times higher for Square, Square-rising, and Square-spike waveforms compared to results reported in [12], [23], in the literature from $2.4 \mathrm{kHz}$ to $8 \mathrm{kHz}$. 


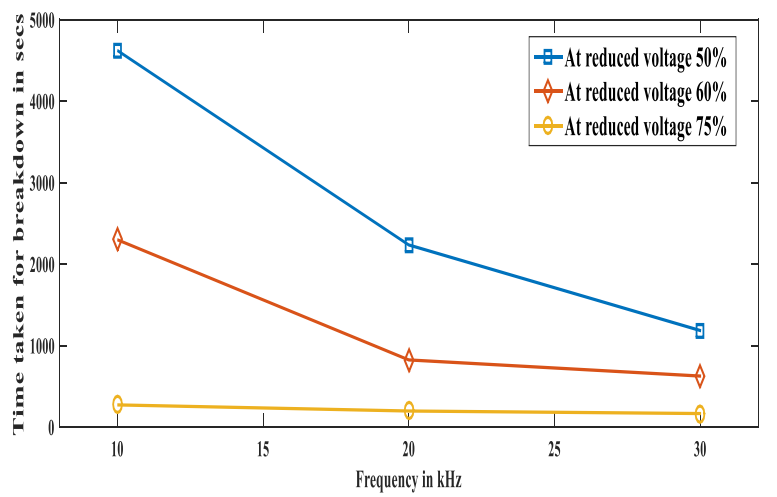

(a)

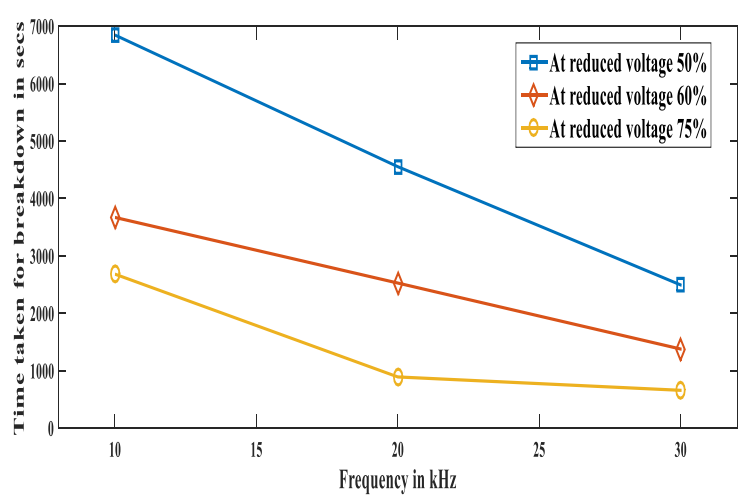

(b)

Figure 6. The change in time with the change in different frequency levels up $30 \mathrm{kHz}$ (a) square-rising waveform b) square-spike waveform

\subsection{Numerical modeling of electric field distribution in twisted pair sample}

In geometrically simplified, a parallel configuration of winding wires without twists, three cases are analyzed; case 1: Two conductors are in direct contact with each other $(\mathrm{g}=0 \mathrm{~mm})$, case 2: Two conductors are separated by a micro gap between them $(\mathrm{g}=0.05 \mathrm{~mm})$ and case 3 : Two conductors are separated by a gap $(\mathrm{g}=0.1 \mathrm{~mm})$. The electric fields of two neighboring wires were numerically modeled using the COMSOL program. For modeling, the polyester enamel thickness was considered to be $40 \mu \mathrm{m}$, and the dielectric constant was assumed as $€_{\mathrm{r}}=3.3$. The applied voltage is the breakdown voltage of the Square-rising and Square waveforms at various levels in frequency in the range of $10-30 \mathrm{kHz}$ observed in the experiment. The electric field distribution of the 2D model of two parallel conductors for all the 3 cases $(\mathrm{g}=0 \mathrm{~mm}, \mathrm{~g}=0.05 \mathrm{~mm}$ $\& \mathrm{~g}=0.1 \mathrm{~mm}$ ) is stressed by the Square-rising waveform at a frequency of $10 \mathrm{kHz}$. The electric field distribution of the 2D model stressed by the Square waveform at a frequency of $10 \mathrm{kHz}$ is similar to the $2 \mathrm{D}$ model designed with a Square-rising waveform. Figure 7 shows the electric field distribution of the 2D model for case $1(\mathrm{~g}=0 \mathrm{~mm})$ of the Square-rising waveform.

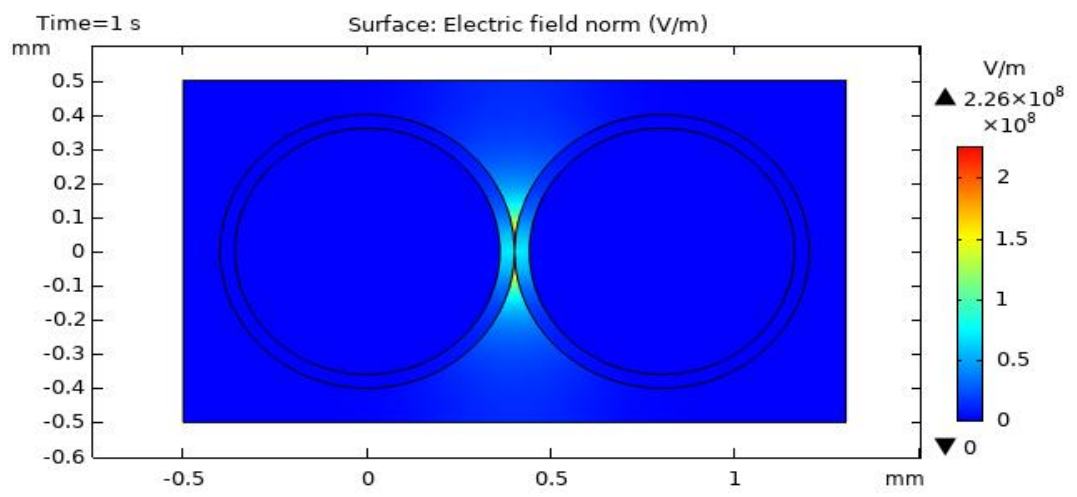

Figure 7. The electric field distribution of square-rising waveform at $10 \mathrm{kHz}$ for case 1

It is noted that for all the 3 cases, the maximum strength of the electric field is on the surface of the wire insulation near the contact location of the wires. In case 2, the reason for reduced electric field strength is because of the narrow air gap with that of the direct contact case. In case 3 , it is noted that the reason for more reduction of field strength is due to the air gap between the wires compared to case 1 and case 2 . However, the electric field on the surface of the wire insulation between the wires is still sufficient to initiate PD for both the waveforms because ionization is surrounding the air gap along with surface potential decay [25]. A similar trend of results reported in [18]. For the increased voltage of $5.65 \mathrm{kV}$, the field value obtained is $46.6 \mathrm{kV} / \mathrm{mm}$. If instead of $1 \mathrm{kV}$ test voltage, $5.65 \mathrm{kV}$ is applied the field would have been $39.55 \mathrm{kV} / \mathrm{mm}$ for the same $0.1 \mathrm{~mm}$ gap. However, the field obtained by [18], is $7 \mathrm{kV} / \mathrm{mm}$ for the test voltage of $1 \mathrm{kV}$. Hence, 
the higher field obtained in this work is due to the high frequency of $10 \mathrm{kHz}$ compared to power frequency and Square-rising wave compared to Sine wave. Besides this, the $€_{\mathrm{r}}$ value of the material used by [18], is 3.84.2 compared to the polyester material used in this work for which the $€_{\mathrm{r}}$ value used is 3.3 . The same is observed for $20 \mathrm{kHz}$ and $30 \mathrm{kHz}$. This shows the effect of high frequency and waveforms on the distribution of field in the air gap between the wires and also on its surface. This can ionize the air in the gap causing spark leading to a thermal runaway as well. So besides, the PD initiated by high frequency stress, ionization may lead to spark in the gap thus triggering the breakdown of enamel insulation. There is a need for the development of a new insulation system for low voltage motors that can withstand higher PD resistance.

Figure 8 shows that there is a variation in the distribution of electric field over the frequency of Square-rising and Square waveforms in all three cases. For cases 1, 2 and 3 the electric field strength is high at $10 \mathrm{kHz}$, and a gradual decrease in electric field strength values at $20 \mathrm{kHz}$ and $30 \mathrm{kHz}$ for both Squarerising and Square waveforms. Further, it is noticed that for all three cases, the electric field strength of the Square-rising waveform is higher than that of the Square waveform for all frequencies.

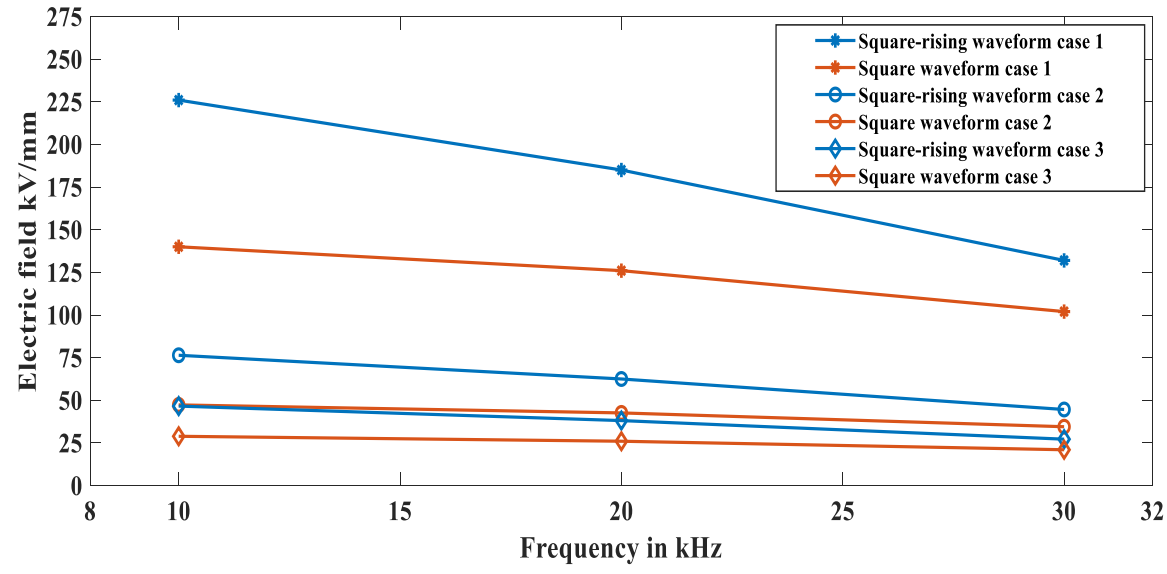

Figure 8. Variation in electric field distribution of Square-rising and square waveforms from $10 \mathrm{kHz}$ to 30 $\mathrm{kHz}$ for case 1 , case 2 , and case 3

\subsection{Numerical modeling of electric field distribution of reduced voltages in twisted pair sample}

A numerical model for reduced voltage of $75 \%, 60 \%$, and $50 \%$ of the breakdown voltage of the Square-rising waveform is considered. The variation in the electric field distribution over the frequency of reduced voltages is shown in Figure 9. However, the electric field observed is high enough to initiate PD for $75 \%, 60 \%$, and $50 \%$ of reduced voltage.

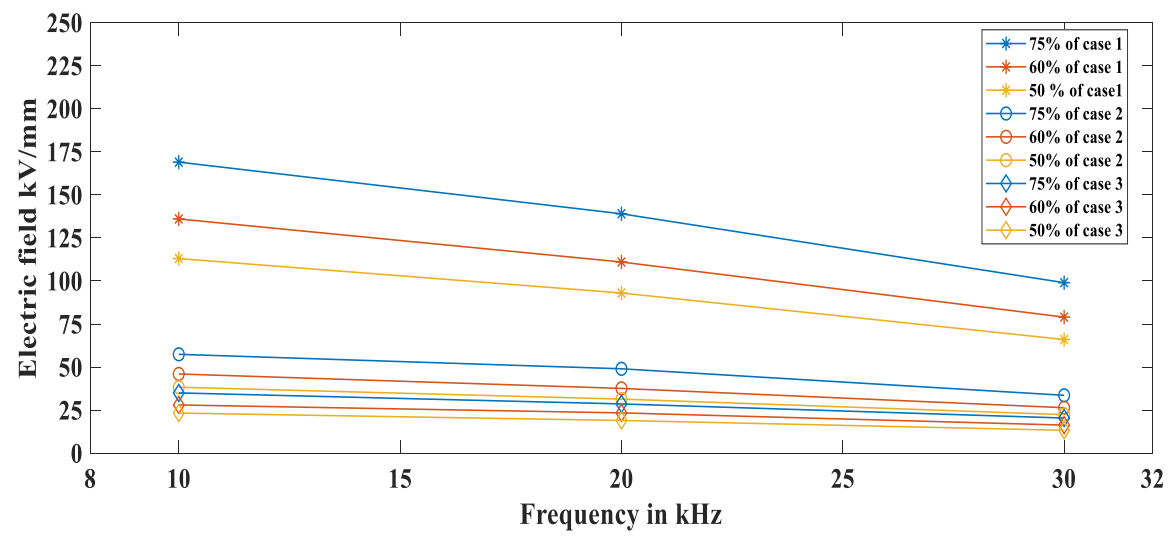

Figure 9. Variation in electric field distribution of Square-rising waveform under reduced voltage from 10 $\mathrm{kHz}$ to $30 \mathrm{kHz}$ for case 1 , case, and case 3 


\section{CONCLUSION}

The high switching frequency is a predominant factor that causes reliability problems in insulation and can be associated with PD activity that accelerates insulation deterioration of the motor winding. After investigating the experimental results it is revealed that for Square-rising waveform the breakdown voltage is high when compared to Square-spike and Square waveforms. It is also observed that while using Square waveform the rate of deterioration of the insulation system is expeditious when compared with Square-spike and Square-rising waveforms. Furthermore, it is also noticed that when the test voltage frequency is enhanced from 10-30 kHz, the lifetime of Square-rising and Square-spike waveforms are two straight lines with higher slope followed by lower slope for all frequencies. From the simulation, it is observed that the electric field values are highest in the gap between the wires including at the surface of wires, and decreasing on the other regions. This implies that the possibility of PD initiating within the enamel. From the simulation results, it is analyzed that the impact of $\mathrm{PD}$ on enamel insulation at higher switching frequencies is so high that the twisted-pair sample fails prematurely. Hence, there is a need for further investigation of designing magnetic wires to withstand high PD resistance in low voltage motors. The important statistical parameter such as PDIV, PRPD pattern stressed by Square waveform needs to be investigated.

\section{REFERENCES}

[1] V. N. Höpner, V. E. Wihelm, "Insulation Life Span of Low Voltage Electric Motors-A Survey," Journal of energies, vol. 14, pp .1-32, 2021, doi: 10.3390/en14061738.

[2] F. Guastavino, C. Gianoglio, E. Torello, M. Ferraris, and W. Gianelli, "Behaviour of Conventional and Nanofilled Impregnation Resins when Subjected to PD Activity," IEEE 2nd International Conference on Dielectrics ICD, 2018, pp. 1-3, doi: 10.1109/ICD.2018.8514692.

[3] L. Lusuardi, A. Cavallini, M. G. de la Calle, J. M. Martínez-Tarifa, G. Robles, "Insulation design of low voltage electrical motors fed by PWM inverters," IEEE Electrical Insulation Magazine, vol. 35, no. 3, pp. 7-15, May-June 2019, doi: 10.1109/MEI.2019.8689431.

[4] Y. Xie, J. Zhang, F. Leonardi, A. R. Munoz, M. W. Degner, F. Liang, "Voltage Stress Modeling and Measurement for Random-Wound Windings Driven by Inverters," IEEE International Electric Machines \& Drives Conference IEMDC, 2019, pp. 1917-1924, doi: 10.1109/IEMDC.2019.8785133.

[5] R. Leuzzi, V. G. Monopoli, F. Cupertino, P. Zanchetta, "Active Ageing Control of Winding Insulation in High Frequency Electric Drives," IEEE Energy Conversion Congress and Exposition ECCE, 2018, pp. 1-7, doi: 10.1109/ECCE.2018.8558257.

[6] Z. Wei, H. You, B. Hu, R. Na, J. Wang, "Partial Discharge Behavior on Twisted Pair under Ultra-short Rise Time Square-wave Excitations," IEEE Electrical Insulation Conference EIC, 2019, pp. 493-496, doi: 10.1109/EIC43217.2019.9046624.

[7] G. C. Montanari, F. Negri, F. Ciani, "Partial Discharge and life behavior of rotating machine wire insulation under PWM waveforms: The influence of inverter characteristics," IEEE Electrical Insulation Conference EIC, 2017, pp. 161-164, doi: 10.1109/EIC.2017.8004619.

[8] G. C. Montanari, P. Seri, "The effect of inverter characteristics on partial discharge and life behavior of wire insulation," IEEE Electrical Insulation Magazine, vol. 34, no. 2, pp. 32-39, March-April 2018, doi: 10.1109/MEI.2018.8300442.

[9] M. G. De La Calle, J. M. Martínez-Tarifa, Á. M. Gómez Solanilla, G. Robles, "Uncertainty Sources in the Estimation of the Partial Discharge Inception Voltage in Turn-to-Turn Insulation Systems," IEEE Access, vol. 8, pp. 157510-157519, 2020, doi: 10.1109/ACCESS.2020.3018870.

[10] R. Leuzzi, V. G. Monopoli, L. Rovere, F. Cupertino, P. Zanchetta, "Analysis and Detection of Electrical Aging Effects on High-Speed Motor Insulation," IEEE Transactions on Industry Applications, vol. 55, no. 6, pp. 60186025, Nov.-Dec. 2019, doi: 10.1109/TIA.2019.2929013.

[11] K. Hameyer, A. Ruf, F. Pauli, "Influence of fast switching semiconductors on the winding insulation system of electrical machines," International Power Electronics Conference (IPEC-Niigata 2018 -ECCE Asia), 2018, pp. 740745, doi: 10.23919/IPEC.2018.8507972.

[12] F. Guastavino, A. Dardano, "Life tests on twisted pairs in presence of partial discharges: influence of the voltage waveform," IEEE Transactions on Dielectrics and Electrical Insulation, vol. 19, no. 1, pp. 45-52, February 2012, doi: 10.1109/TDEI.2012.6148501.

[13] P. Wang, C. Zheng, Y. Li, Y. Lei, A. Cavallini, "The PD and Endurance Features of Enameled Wires at Short Repetitive Impulsive Voltages," IEEE Electrical Insulation Conference EIC, 2018, pp. 572-576, doi: 10.1109/EIC.2018.8481043.

[14] F. Guastavino, L. Briano, F. Gallesi, E. Torello, "Corona resistant insulating systems characterization for low voltage rotating machine," IEEE Conference on Electrical Insulation and Dielectric Phenomena CEIDP, 2019, pp. 694-697, doi: 10.1109/CEIDP47102.2019.9009901.

[15] I. F. Radzi, N. H. N. Ali, N. Rameli, A. M. Ariffin, M. S. A. Rahman, M. R. Ahmad, A. S. Salleh, "Partial Discharge Detection Device Using Ultrasonic Sensor on Medium Voltage XLPE Cable," Indonesian Journal of Electrical Engineering and Computer Science, vol. 17, no. 2, pp. 886-894, 2020, doi: 10.11591/ijeecs.v17.i2.pp886-894. 
[16] A. Azmi, K. Y. Lau, N. A. Ahmad, Z. A. Malek, C. W. Tan, "Electrical Breakdown and Chemical Properties of Polypropylene / Calcium Carbonate Nanocomposites," Indonesian Journal of Electrical Engineering and Computer Science, vol. 20, no. 2, pp. 563-568, 2020, doi: 10.11591/ijeecs.v20.i2.pp563-568.

[17] M. Florkowski, B. Florkowska, P. Zydron, "Partial Discharges in Insulating Systems of Low Voltage Electric Motors Fed by Power Electronics-Twisted-Pair Samples Evaluation," Journal of energies, vol. 12, no. 5, pp. 1-19, 2019, doi: 10.3390/en12050768.

[18] A. Mirza, W. Chen, H. Nguyen, Y. Cao, A. M. Bazzi, "High-Voltage High-Frequency Testing for Medium-Voltage Motor Insulation Degradation," IEEE Energy Conversion Congress and Exposition ECCE, 2018, pp. 2444-2447, doi: 10.1109/ECCE.2018.8557568.

[19] S. N. Rao, K. Elanseralathan, "Influence of PWM technique on breakdown in twisted pairs," 3rd International Conference on Condition Assessment Techniques in Electrical Systems CATCON, 2017, pp. 427-431, doi: 10.1109/CATCON.2017.8280258.

[20] F. Guastavino, A. Dardano, E. Torello, "Measuring partial discharges under pulsed voltage conditions," IEEE Transactions on Dielectrics and Electrical Insulation, vol. 15, no. 6, pp. 1640-1648, December 2008, doi: 10.1109/TDEI.2008.4712668

[21] K. Zhou, T. Tao, Y. C. Hung, X. T. Li, W. Zhao, "The Effect of Different Rise Time on Partial Discharge Activity of Inter-Turn Insulation Under Square Wave Voltage," International Transactions on Electrical Energy Systems, vol. 23, pp. 1083-1094, 2013, doi: 10.1002/etep.1639.

[22] F. Guastavino, A. Ratto, S. Squarcia, E. Torello, "Electro-thermal aging tests on different kinds of enamelled wires," 10th IEEE International Conference on Solid Dielectrics, 2010, pp. 1-4, doi: 10.1109/ICSD.2010.5568020.

[23] F. Guastavino, D. Cordano, E. Torello, L. Della Giovanna, "PD evolution of conventional and corona resistant enamels," IEEE Conference on Electrical Insulation and Dielectric Phenomena CEIDP, 2016, pp. 259-262, doi: 10.1109/CEIDP.2016.7785686.

[24] G. C. Montanari, P. Seri, R. Hebner, "Type Of Supply Waveform, Partial Discharge Behavior And Life Of Rotating Machine Insulation Systems," IEEE International Power Modulator and High Voltage Conference IPMHVC, 2018, pp. 176-179, doi: 10.1109/IPMHVC.2018.8936775.

[25] T. Hoang, Y. V. Serdyuk, S. M. Gubanski, "Mechanisms of surface potential decay on enamel wire coatings," IEEE Transactions on Dielectrics and Electrical Insulation, vol. 22, no. 6, pp. 3470-3480, December 2015, doi: 10.1109/TDEI.2015.005223.

\section{BIOGRAPHIES OF AUTHORS}
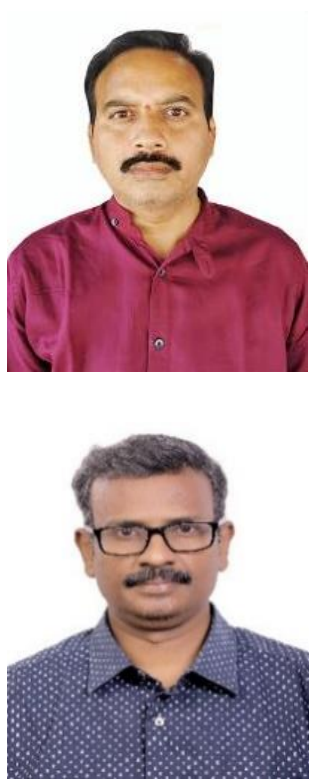

S Narasimha Rao was born in Srikalahasthi in 1977. He received his B.Tech degree from S.V College of Engineering, S.V University in 2004 and M.E degree from Sathyabama University Chennai, India in 2010. He is a research scholar in the Department of EEE, Puducherry Technological University, Puducherry, India, and his areas of interest are insulation in motor windings, space charge measurement, modeling on insulation.

Elanseralathan K was born in Puducherry in 1971. He received his B.Tech degree from Mahatma Gandhi University, Kottayam in 1992, M.E degree from the Indian Institute of Science, Bangalore, India in 1999, and Ph.D. degree from the Indian Institute of Technology Kanpur, India in the year 2009. He is currently working as a Professor in the Department of EEE, Puducherry Technological University, Puducherry, India, and his areas of interest are Partial discharge, modeling of insulation, nano dielectrics, and energy storage. 